\title{
Reflexões sobre a inserção do Ensino Híbrido nas séries finais do ensino fundamental nas aulas de Língua Portuguesa
}

\author{
Daniela Duarte Ilhesca ${ }^{1}$, Aline de Campos ${ }^{2}$ \\ ${ }^{1}$ Prefeitura Municipal de Canoas - Canoas - RS - Brasil e CINTED - Universidade \\ Federal do Rio Grande do Sul (UFRGS) - Porto Alegre - RS - Brasil \\ ${ }^{2}$ Programa de Pós-Graduação em Informática na Educação - Universidade Federal do \\ Rio Grande do Sul (UFRGS) - Porto Alegre - RS - Brasil \\ \{daniela.ilhesca, alinedecampos\}gmail.com
}

\begin{abstract}
The qualification of teaching and learning of the Portuguese Language subject goes through the integration of technology, new media and new methodologies. This article presents data on an exploratory research case study - conducted with two 9th grade students in a municipal school by applying two active methodologies: Individual Rotation and Inverted Classroom. The results reveal that these classes give teachers a new way of teaching, and students a more active stance to learn.
\end{abstract}

Resumo. A qualificação do ensino e aprendizagem da disciplina da Língua Portuguesa perpassa pela integração da tecnologia, de novas mídias e de novas metodologias. Este artigo apresenta dados acerca de uma pesquisa exploratória - estudo de caso - realizada com alunos de dois $9^{\circ}$ s anos em uma escola municipal por meio da aplicação de duas metodologias ativas: Rotação Individual e Sala de Aula Invertida. Os resultados revelam que essas aulas concedem aos professores uma nova maneira de ensinar, e aos alunos uma postura mais ativa para aprender.

\section{Introdução}

A sala de aula, nas escolas públicas em nosso país, por via de regra, está aquém do que os alunos necessitam, visto que o mundo está em transformação, e os recursos digitais não têm feito parte da totalidade da educação. Não há como negar que a brasileira, em especial à básica, vive uma crise e os seus índices de qualidade encontram-se baixos.

Com o avanço da tecnologia, o foco dos alunos é outro, pois vivem em uma realidade permeada pela alta velocidade das informações, facilitando o acesso ao conhecimento. Dessa forma, acompanhando essa tendência, despontaram novas possibilidades nos modos de ensinar e aprender. Nesse ínterim, as metodologias ativas, em especial, o Ensino Híbrido - muito utilizado na educação superior - oportuniza a combinação do uso das tecnologias digitais com as interações presenciais. Ou seja, um misto do ensino tradicional - presencial e no ambiente da sala de aula física - com ensino online - virtual e em qualquer tempo e espaço.

Dessa forma, a disciplina de Língua Portuguesa, conforme a Base Nacional Comum Curricular - BNCC (BRASIL, 2018), não pode se abster às mudanças, e as aulas expositivas, às vezes, nem dialogadas, devem ceder lugar às atividades que propiciem desafios e problemas aos alunos através de diferentes culturas midiáticas. 
VIII Congresso Brasileiro de Informática na Educação (CBIE 2019)

Anais do XXV Workshop de Informática na Escola (WIE 2019)

Para o atendimento à problemática da pesquisa, elencou-se como objetivo geral avaliar se o desenvolvimento de atividades baseadas no Modelo Híbrido de Ensino colaboram na prática pedagógica da Língua Portuguesa nas séries finais do Ensino Fundamental.

Para isso, a seção 2 trata do contexto teórico, envolvendo as metodologias ativas: sala de aula invertida e rotação individual. A seção 3 descreve o método utilizado e a população, além da forma como os dados foram levantados e analisados. Já a seção 4 apresenta e discute a análise dos dados relativos às impressões dos alunos e da pesquisadora, bem como o questionário aplicado no Google Forms, e, na última seção, sintetizam-se os principais pontos de análise relativos ao tema da investigação, trazendo, também, sugestões para futuros trabalhos.

\section{Metodologias Ativas}

Aprende-se de modos diversos e com estratégias diferentes, no entanto há a necessidade de se distinguir qual o modelo mais eficaz para alcançar os objetivos almejados em determinada situação. Por isso, em certos momentos, a fuga aos modelos tradicionais e rígidos torna-se uma necessidade ao desenvolvimento da aprendizagem significativa.

Nesse sentido, as Metodologias Ativas (MA) são uma concepção educacional que viabiliza aos alunos tornarem-se os principais agentes do aprendizado. Estimular a crítica e a reflexão são princípios fundamentais para isso, por meio da condução do professor em sala de aula, propiciando ao aluno a construção e reconstrução do conhecimento. Em contrapartida à aprendizagem passiva, centrada em transmitir informações, o aluno assume uma atitude de protagonismo.

O princípio basilar deste modelo de ensino é o incentivo aos alunos, a fim de que aprendam de forma independente e participativa, a partir de situações verdadeiras. Eles passam de ouvintes a atores, tornando-se peças principais do processo, e o professor, coadjuvante, orientando-os nessa caminhada. Segundo Borges e Alencar (2014), esse contexto pode "favorecer a autonomia do educando, despertando a curiosidade, estimulando tomadas de decisões individuais e coletivas, advindos das atividades essenciais da prática social e em contextos do estudante" (p.120).

A aprendizagem ativa acontece eficazmente, no momento em que o aluno interage com a temática a ser estudada, questionando-a, resolvendo-a, formulando hipóteses e futuras ações, tornando-se capaz de produzir uma postura independente e crítica. Um dos modos de se colocar em prática a MA é através dos modelos híbridos: rotação individual e sala de aula invertida

No primeiro, o aluno tem um roteiro de estudo que pode ser programado por ele ou pelo professor, organizado de acordo com suas pretensões e no tempo que precisarem. No segundo, a teoria é estudada em casa, no formato online, e o espaço da sala de aula é empregado para discussões, resolução de atividades, entre outras proposições. A explicação do conteúdo é agora realizada em casa, e a aplicação, em sala de aula. Assim, conforme Valente (2015), existe um incentivo à responsabilidade por parte do estudante "que assume uma postura mais participativa, resolvendo problemas, desenvolvendo projetos [...] criando oportunidades para a construção de seu conhecimento. O professor tem a função de mediador, consultor do aprendiz" (p. 15). 
VIII Congresso Brasileiro de Informática na Educação (CBIE 2019)

Anais do XXV Workshop de Informática na Escola (WIE 2019)

É imprescindível destacar que, para aplicação de qualquer um desses modelos de ensino híbrido, deve haver uma mudança na postura dos alunos, do professor e do próprio ambiente escolar como um todo.

\section{Procedimentos metodológicos}

A pesquisa aplicada caracterizou-se como um estudo de caso com abordagem qualitativa e quantitativa, propondo-se a avaliar se as metodologias ativas qualificam o ensino presencial da Língua Portuguesa e o pleno desenvolvimento dos alunos no ensino fundamental. De acordo com Dal-farra e Lopes (2013), a concepção de pesquisas com métodos mistos apresenta boa relevância na área de Educação "desde que os pesquisadores saibam identificar com clareza as potencialidades e as limitações no momento de aplicar os métodos em questão" (p.71).

Organizaram-se propostas de ensino e aprendizagem baseadas em metodologias ativas - Rotação Individual e Sala de Aula Invertida - as quais foram aplicadas pela pesquisadora/professora em suas aulas de Língua Portuguesa. Fez-se a opção por elas, em virtude de que a escola não possui um laboratório de informática funcionando e não tem internet disponível para os alunos em sala de aula.

O estudo foi realizado em uma escola de educação básica e justifica-se a escolha desta instituição, por ser o local em que a pesquisadora/professora exerce sua função docente, o que facilitou a proposição dessa prática pedagógica com metodologias ativas.

Os sujeitos da investigação foram 58 alunos, de duas turmas de $9^{\circ} \mathrm{s}$ anos $-9^{\circ} \mathrm{A}$ e $9^{\circ} \mathrm{B}$ do turno da manhã. Esta totalizando 29 alunos, sendo 17 do gênero masculino e 12 do gênero feminino; e aquela, 29 alunos, com 18 do gênero masculino e 11 do gênero feminino. A média de idade dos pesquisados é de 15 anos.

A intervenção da pesquisa foi realizada em 6 dias, com 12 períodos de 55 minutas cada, totalizando 11 horas em sala de aula, além dos horários utilizados pelos alunos fora do contexto escolar em outros locais. Os pesquisados, durante a prática, desenvolveram atividades em dois locus - na sala de aula na Escola e em casa, envolvendo os conteúdos de Crase e Texto Dissertativo.

Em relação à sequência didática desenvolvida, na primeira aula, a metodologia ativa Rotação Individual foi apresentada aos alunos, orientando-os na sua utilização para a aprendizagem do conteúdo nos próximos períodos de aula através do site criado com materiais selecionados pela docente.

$\mathrm{Na}$ segunda e terceira aulas, procedeu-se a socialização, através das falas espontâneas dos alunos, da experiência com a metodologia ativa Rotação Individual como parte do aprendizado sobre a Crase, salientando, sempre, a importância do acesso de todos ao site. Após, realizou-se a retomada dos pontos principais levantados pelos alunos e das dificuldades que sentem na utilização do acento.

Na quarta aula, ocorreu o detalhamento da Sala de Aula Invertida, próxima proposta de trabalho, envolvendo o Texto Dissertativo. Na quinta e sexta aulas, novamente, um momento de socialização, através das falas espontâneas dos alunos, da experiência com a metodologia ativa Sala de Aula Invertida. Além disso, os alunos explicaram o conteúdo visto em casa, a partir da experiência com a metodologia ativa, e o professor retomou os pontos elencados como mais complicados.

Vale ressaltar que as experiências foram registradas, diariamente, pela pesquisadora, de forma descritiva, através de notas de campo, a partir das conversas 
VIII Congresso Brasileiro de Informática na Educação (CBIE 2019)

Anais do XXV Workshop de Informática na Escola (WIE 2019)

informais com os pesquisados. Ao final das aulas desenvolvidas, foi realizado um diagnóstico das duas turmas por meio de um questionário no Google Forms para identificação do perfil, o domínio tecnológico, bem como a percepção acerca da MA.

\section{Resultados e discussões}

Dos 58 alunos, somente 7 não responderam e 4 não autorizaram a utilização dos dados da investigação, constituindo uma amostra total de 47 participantes. A faixa etária dos alunos corresponde a um intervalo entre 14 e 17 anos, em que 53,1\% dos alunos está com 15 anos; 23,4\% corresponde a 14 anos; 10,6\%, a 16 anos e 12,7\%, a 17 anos.

Em relação aos tipos de equipamentos digitais disponíveis em casa - percebe-se a predominância de dispositivos móveis como o smartphone com $89,4 \%$ e o iphone com $12,8 \%$, seguidos pelo notebook $(59,6 \%)$, computador de mesa $(46,8 \%)$, videogame $(51,1 \%)$ e tablet $(14,9 \%)$, evidenciando que, de fato, o celular se transformou no principal dispositivo de acesso às informações.

A principal forma de acesso à Internet é a banda larga utilizada em casa, seguida pelo celular. Há a presença de um cenário favorável à adoção da metodologia híbrida porque todos os alunos possuem esse recurso para fazer atividades online.

O principal equipamento usado para acessar à internet é o smartphone, totalizando $72,3 \%$, seguido pelo computador de mesa, $10.6 \%$. Referente ao tempo de lazer utilizado com um dispositivo digital, os discentes $(31,9 \%)$ relataram que o usam praticamente o dia todo; 29,8\%, 4 horas; de 3 a 4 horas, uma média de 23,4\%; de 2 a 3 horas, uma média de 6,4\%; de 1 a 2 horas 6,4\% e menos de 1 hora, apenas um aluno, com 2,1\%. No tocante à utilização de algum dispositivo digital para estudo, evidencia-se que 42,6\% utiliza entre 1 a 2 horas; 38,3\% menos de 1 hora; $10,6 \%$, de 2 a 3 horas; $6,4 \%$, de 3 a 4 horas e, praticamente, o dia todo, 2,1\%.

Como não se valer da grande maioria, que se conecta praticamente o dia todo, a não ser na escola, no caso específico desse estudo, em função da inviabilidade física, e propiciar, a construção do conhecimento permeado pelos espaços digitais. Para Moran (2015), a educação torna-se blended, por não ocorrer exclusivamente nos bancos escolares, porém ultrapassando esses limites físicos e indo ao encontro do verdadeiro saber em ininterrupta construção e reconstrução.

Os alunos estudam por dia em casa de 1 a 2 horas $(36,2 \%)$ e menos de 1 hora (29,8\%). Além disso, um percentual considerável de 17\% (8 alunos) não estuda. Esse questionamento denota o baixo comprometimento das turmas com o ato de estudar, uma vez que ninguém se dedica além de 3 horas por dia.

Os alunos utilizam recursos tecnológicos em seu dia a dia e deve-se tentar agregá-los mais ainda em seu cotidiano escolar. De acordo com Lopes (2015), a sala de aula troca de lugar, e o professor não está mais "à frente", porém "em meio", mediando o processo de aprendizagem, retificando caminhos e propondo novas trajetórias, através da utilização de dois subsídios básicos e imprescindíveis: o celular e o computador.

O quadro branco é uma unanimidade entre os professores, assim como o não aproveitamento do laboratório de informática. Pode-se destacar outras mídias relevantes no cotidiano escolar: a utilização de filmes, de apresentação de slides, da televisão, de jornais e revistas, dos livros, de áudios - recursos mais acessíveis na escola.

Sabe-se da importância do emprego de recursos didáticos no processo de ensino aprendizagem tanto para o aluno quanto para o professor, e estes gostaram de acessar os 
VIII Congresso Brasileiro de Informática na Educação (CBIE 2019)

Anais do XXV Workshop de Informática na Escola (WIE 2019)

conteúdos através do site, bem como da proposição das aulas nesta abordagem, só revelaram, em suas falas, que não estão acostumados a fazer atividades escolares em casa e isso se tornou um empecilho em alguns momentos, pois utilizam o celular e computador para lazer. Esse é um ponto que precisa ser revisado, a fim de que uma rotina se estabeleça nesse nível de ensino.

\section{Considerações finais}

Esta experiência didática proporcionou desvelar uma proposta voltada para o ensino fundamental, baseada em duas metodologias ativas - Rotação Individual e Sala de Aula Invertida -, a fim de trazer subsídios que possam alavancar esse tipo de abordagem na educação básica.

Vale ressaltar que, na rede municipal em questão, isso tudo é muito recente e, em vista disso, esse trabalho pretendeu fazer uma análise das possibilidades de inserção da tecnologia aliada ao ensino híbrido na última série do ensino fundamental - $9^{\circ}$ ano.

Verificou-se que a utilização das mídias digitais despertou um maior envolvimento dos alunos na execução das atividades indicadas, propiciando um espaço diferenciado de apreensão do conhecimento, mediado pelo professor e protagonizado pelos estudantes.

Finalizando, recomenda-se o prosseguimento dessa proposta mediada por Metodologias Ativas como prática pedagógica arrojada nesse contexto educativo em específico, objetivando o amplo desenvolvimento dessa concepção híbrida de educação, priorizando o maior envolvimento do aluno, não só individualmente, mas também coletivamente.

\section{Referências}

Borges, T. S; Alencar, G. (2014) "Metodologias ativas na promoção da formação crítica do estudante: o uso das metodologias ativas como recurso didático na formação crítica do estudante do ensino superior". Cairu em Revista; n 04, p. 1 19-143.

Brasil. Ministério da Educação (2018) "Base Nacional Comum Curricular". Secretaria de Educação Básica. Brasília.

Dal-farra, R. A.; Lopes, P. T. C. (2013) "Métodos Mistos de pesquisa em educação: pressupostos teóricos". Nuances, v.24, p.67-80.

Lopes, A. (2015) "Tudo junto e misturado". Revista Rede Educa - Tecnologia para Educação. São Paulo. Disponível em: em: $<$ http://www.arede.inf.br $>$

Valente, J. A. (2015) "Prefácio". In: Bacich, Lilian; Tanzi Neto, Adolfo; Trevisani, Fernando De Mello (orgs.). Ensino híbrido: personalização e tecnologia na educação. Porto Alegre: Penso, p. 13-17. 